\title{
A True Comparison of Processed vs 'Natural' Sugars
}

\author{
Danielle Bellmer ${ }^{1 *}$ and William McGlynn ${ }^{2}$ \\ ${ }_{1,2}$ Robert M Kerr Food and Agricultural Products Center, Oklahoma State University, USA
}

*Corresponding author: Danielle Bellmer, Department of Robert M Kerr Food and Agricultural Products Center, Oklahoma State University, USA.

Received Date: July 24, 2019

Published Date: August 13, 2019

\section{Mini Review}

Health fads come and go, and in the recent past our food enemies have included fat, eggs, and gluten. In today's health news, sugar has become a very controversial topic. High fructose corn syrup (HFCS) has become the new enemy. In addition, there seems to be an assumption that 'real sugar' or 'natural sugar' is somehow healthier. It's not. It is still sugar.

Sugar can be found in many different forms, and today in many parts of the world, including the Americas and Europe, most of it comes from three sources: sugar cane, sugar beets, and corn. The sugar from cane and beets is in the form of sucrose (table sugar), which is a disaccharide containing equal parts glucose and fructose. High fructose corn syrup is the sugar derived from the modification of corn starch, also containing glucose and fructose. Many food manufacturers prefer to use corn syrup because it's cheaper and easier to use, but HFCS has recently been under attack. Opponents claim that it is artificial, unnatural, and that fructose consumption is harmful. Nutritionally speaking, cane sugar and HFCS are nearly identical. Sucrose is made up of $50 \%$ fructose and $50 \%$ glucose, and the most commonly used grades of HFCS also contain approximately equal parts fructose and glucose. HFCS 55 contains 55\% fructose and $45 \%$ glucose, and HFCS 42 contains $42 \%$ fructose and $58 \%$ glucose U.S. FDA, $[1,2]$. In many cases, HFCS actually contains less fructose than cane sugar.

In recent years, fructose has been under attack, and has been blamed for numerous health issues. But most studies showing negative health results due to fructose intake have extremely exaggerated the levels of fructose intake, which is unrealistic, and is not useful for predicting real health outcomes White [3]. Most scientists agree that there is no real evidence that suggests fructose intake causes any health results that are different than other sugars.

In response to the fructose negativity, some food manufacturers have begun to replace HFCS with other sources of sugar. In addition, there are a plethora of new terms used to describe our traditional sugar sources that are meant to sound 'natural' and more appealing, including terms such as 'cane crystals', 'real cane sugar', and 'evaporated cane juice'. Guess what? It's still sugar.

The U.S. Food and Drug Administration (FDA) does not enforce a formal definition of "natural sugar" for food labeling purposes, although the agency does consider the term "natural" to imply that nothing artificial or synthetic has been added to a food. "Natural" has not yet been determined by the FDA to imply anything about food production or processing methods or about a food's nutritional or other possible health benefits U.S. FDA, [4]. Thus, "natural sugars" is primarily a marketing term that could at present be applied to all non-artificial sweeteners.

Table 1: Glucose and Fructose Content of Some Common Sweeteners.

\begin{tabular}{|l|c|c|c|}
\hline Sweetener & Total Sugars \% & Glucose \% & Fructose \% \\
\hline Agave Syrup $^{[5]}$ & 68 & 12 & 56 \\
\hline Coconut Sugar $^{[7]}$ & $95-100$ & $45-50$ & $45-50$ \\
\hline HFCS-55 $^{[1]}$ & $97-100$ & 42 & 55 \\
\hline USDA $^{[6]}$ & 82 & 36 & 41 \\
\hline Maple Syrup $^{[8]}$ & 60 & 30.5 & 29.5 \\
\hline${\text { HFCS }-4^{[1]}}^{[1]}$ & $97-100$ & 55 & 42 \\
\hline HFCS -55 & $97-100$ & 42 & 55 \\
\hline Cane Sugar & 100 & 50 & 50 \\
\hline
\end{tabular}

Traditional table sugar (cane sugar) essentially consists of $100 \%$ sucrose, which as noted above is itself composed of equal parts glucose and fructose. Many competing "natural sweeteners" have become popular due to their assumed superior health benefits compared to cane sugar. These novel sweeteners include products such as honey, agave syrup [5,6] or nectar, coconut sugar, and maple syrup $[7,8]$. Interestingly, coconut sugar and maple syrup have essentially the same sugar composition as sucrose-about $50 \%$ glucose and $50 \%$ fructose, and agave syrup actually contains much higher levels of fructose, up to $70-90 \%$ by weight, depending on how it is processed. (Table 1) shows a comparison of glucose and fructose contents of some common sweeteners. 
When eaten in their raw, unprocessed form, some of these sweeteners may indeed have additional health benefits such as vitamins, minerals, or antioxidants that would typically be removed or degraded during the refining process. However, most of the syrups and sweeteners sold to consumers have been processed and contain very low levels of any additional nutrients Ajibola et al. Theriault et al. $[9,10]$. In any case, one would have to consume unreasonably large quantities of any raw sweetener to see any significant increase in nutrient intake. There is no harm in eating raw sugars, but their health impact is likely negligible, and some consumers may in fact eat more sugar than they otherwise would in the mistaken assumption that raw sugars are "healthy."

From a health perspective, many nutritionists believe that the problem today is not the type of sugar being used, but the ubiquity of foods with high sugar content. Sugar is added to many common foods, and we have grown accustomed to high levels of sweetness in almost everything we eat including condiments, salad dressings, and all kinds of snacks. Rather than focus on the search for natural sugar, most of us could benefit simply by eating less sugar overall. The best way to consume natural sugars is by eating whole fruit; that way we reap the benefits of all the fiber and vitamins and minerals that occur naturally in fresh fruit. Looking at the chemical breakdown of these natural sugars, it is clear that the differences between them are not such that our bodies are likely to respond differently based on the type of sugar we consume. In the end, processed sugar is just sugar.

\section{Acknowledgement}

None.

\section{Conflict of Interest}

No conflict of interest.

\section{References}

1. White JS (2008) Straight talk about high-fructose corn syrup: what it is and what it ain't. Am J Clin Nutr 88(6): 1716S-1721S.

2. (2018) U.S. Food and Drug Administration. High fructose corn syrup questions and answers.

3. White JS (2013) Challenging the fructose hypothesis: new perspectives on fructose consumption and metabolism. Adv Nutr. Adv Nutr 4: 246256.

4. (2016) U.S. Food and Drug Administration. The FDA Requests Comments on Use of the Term "Natural" on Food Labeling.

5. (2019) U.S. USDA. Agave syrup. USDA National Nutrient Database.

6. (2019) U.S. USDA. Honey. USDA National Nutrient Database.

7. Johnson J (2018) Coconut sugar: Is it good for you? Medical News Today.

8. (2019) U.S. USDA. Maple Syrup. USDA National Nutrient Database.

9. Ajibola A, Chamunorwa JP, Erlwanger KH (2012) Nutraceutical values of natural honey and its contribution to human health and wealth. Nutr Metab 9: 61.

10. Theriault M, Caillet S, Kermasha S, Lacroix M (2006) Antioxidant, antiradical and antimutagenic activities of phenolic compounds present in maple products. Food Chemistry 98(3): 490-501. 